\title{
Cultural Semiotics and the Related Interpretation
}

\author{
Jinshun Long ${ }^{1 * a}$, Jun $\mathrm{He}^{2 \mathrm{~b}}$ \\ ${ }^{1}$ School of Foreign Languages, Jimei University, Xiamen, Fujian, China \\ ${ }^{2}$ School of Architecture and Civil Engineering, Jinggangshang University, Ji'an, Jiangxi, China \\ a*Jinshun Long. jslong123@sina.com \\ b412096955@qq.com
}

\begin{abstract}
This study is intended to expatiate on some key concepts in cultural semiotics, analyze the characteristics and functions of cultural semiotics, and indicate the importance of semiotic analysis. It defines the interaction between semiotics and culture through language symbols, shows the relationship between semiotics and culture, and discusses signification of different levels, semiosphere, semiotic space,etc., offering a more uniform and dynamic vision of cultural semiotics, which is of great significance for us to renew and deepen our understanding of cultural space and to recognize human culture in essence.
\end{abstract}

Keywords: cultural semiotics, related interpretation.

\section{INTRODUCTION}

Semiotics has always been involved in two kinds of research activities: one is the incessant exploration into the basic theories of semiotics; the other is the concrete analyses carried out in various fields of research. As a typical interdisciplinary theory, semiotics is both a branch of knowledge and a new methodology. The contents of semiotics cover various disciplines, and its methods also originate from them. In the course of its development, semiotics has drawn on the research results from philosophy, logics, linguistics, psychology, culturology, literary theory, and communication media, etc., incorporating all these into the same framework of methodology, regarding them as different representations of the generation, transmission and interpretation of meanings. These disciplines constitute the actual application of semiotics, while semiotics plays a role of organizing science for these disciplines.

\section{CULTURE AND SEMIOTICS}

Lotman defined culture as collective non-genetic memory. Because culture is not inherited, it must be in line with socialization; since it is collective, socialization must be in line with the exchange of information, that is, on symbols. Thus, culture as memory includes not only the content of memory (for example, a stable set of values about family, country, education, clothing, etc.), but also the process by which memory is built from the information collected, exchanged, and stored. What's more, because culture is a social process, it tends to change. Culture is the process through which humans define and operate a limit that relates to the natural basis of our lives and our understanding of the non-human parts of the world around us. This process unfolds through interwoven sub-processes: material production, symbolic production, and institutional organization, which construct a defined, coded, traditional cultural world [1].

In the research of cultural activities, the scholars studying semiotics regard any object or action meaningful to any member in a cultural group as a symbol, attempting to identify rules or conventions of codes hidden in the generation of meanings within that culture. Understanding these codes, the relationships between them, and the contexts in which they are applicable is part of what it means to belong to a particular culture. Marcel Danesi argues that culture can be given a definition as a sort of "macro code", made up of a variety of codes habitually used by a group of individuals to explain reality [2].

Learning these codes requires accepting the values, assumptions and world outlooks embedded within them, often without realizing how much they interfere with the construction of reality. The existence of these codes for text interpretation becomes even more apparent when we study text produced within and for a different culture, such as an advertisements produced for the domestic market in a different country. Interpreting the text in the 
intended way may require "cultural competence" related to the particular cultural context in which the text was produced, even if the text is primarily visual.

Human beings with competence of handling symbols are not only capable----like other animals----of accommodating to the natural environment and transforming them into an environment where they live. In significant measure, we can also modify the given environments and, in many cases, expand the boundaries of that environment. Definitely, there are biological and spiritual conditions that define our species, and parts of our physical environments that we cannot change, but through a constant process of reinvention, our environment is transformed into a leaf in history. To the degree that the cultural process is connected with the semiotic process, which is the subject of cultural semiotics. Eco expounds this in the following words:

Independently of the ways in which they are used to designate objects or states, symbols refer to the system of units in which the various cultures organizes their conception of the world...cultural structures (the ways in which it receives, analyzes and transforms) are semiotic structures and therefore systems of units each can stand for another.

Human culture is a dynamic process: to some extent that it can select what is integrated and what is omitted, that is, it can choose codes and contexts for perceived hierarchical arrangements. This is because it has such a semiotic system as language [4].

\section{CULTURAL SEMIOTICS}

Cultural semiotics is the study of culture as a symbol or semiotic system. This kind of research treating symbols or the semiotic system as having meanings is not only a cultural academic perspective, but more importantly, it involves the definition of the essential characteristics of culture. Taylor defined the cultural world as the all-encompassing collection of human spiritual and material elements, including thought, behavior, literature, art, legal system, material products and so on [5]. The effect of this classical definition is that culture has long seemed indistinguishable from society, ideology, literature, art, and tools.

Unlike Taylor's definition of culture, cultural semiotic theory, which originated from sociologist Max Weber and anthropologist Clifford Geertz, is essentially equivalent to claiming that the essence of culture lies in symbols, or simply that culture equals symbols, the representation system of human beings. The study of culture, therefore, is the study of the symbols or the representation system used by human beings.

The school of British cultural studies, represented by Stuart Hall, extended the study of cultural symbols to the cultural patterns of modern industrial societies, and even to include youth subculture research work, thus forming various international results of the research on contemporary popular cultural semiotics. It should be said that cultural anthropology and contemporary popular cultural semiotics, the two academic development routes are two important fields in which the study of cultural semiotics in the broad sense has made considerable progress. In this sense, to discuss the background of the formation of cultural semiotics theory, we must involve the research results of the above two aspects.

On the other hand, cultural semiotics in its narrow sense overlaps and differs from the studies of cultural anthropology or contemporary popular culture in its academic goals. The overlap lies in that both regard culture as a kind of symbol or a kind of symbolic system and share the same understanding of the essential characteristics of culture. The difference lies in that the academic goal of the studies of cultural anthropology and contemporary popular culture is to study culture itself (local culture or contemporary subculture), while cultural semiotics in its narrow sense has a relatively independent pursuit in discipline construction. Therefore, cultural semiotics here is more interested in the patterned construction of culture in order to generalize the theoretical paradigm suitable for general semiotic research. The representative figures of this development route are Yuri Lotman and Moscow-Tartu School of Cultural Semiotics. At present, the cultural semiotics discussed in the academic circle basically belongs to the narrow sense of cultural semiotics.

Cultural semiotics takes the semiotic process as the starting point and studies the cultural process and its premise as well as the structure of the cultural universe.It draws on semiotic viewpoints and methods to analyze all kinds of physical, mental and behavioral phenomena, including popular culture, art, architecture, cinema, television, musicology, and drama theory, advertising, visual media, etc. As one of the humanities closely associated with such fields as thought, culture and art, semiotics has been of unique cultural features since its birth date.

To a semiotician (a person who analyzes semiotics), a word, a text, a shirt, a hairstyle, a television image, anything can be treated as a symbol, as a piece of information that needs to be decoded and analyzed to find out its meaning. Every cultural activity for a semiotician leaves a trace of meaning, a sort of dot on the Richter scale of semiotics, for us to decipher, just as a geologist "read" the earth for a sign of an earthquake, a volcano, and any other geological phenomenon [6].

In the 1980s, Yuri Lotman began to develop a semiotic approach to the study of culture that was no longer based on the distinction between code and text, but on how information was embedded in a fluid semiotic environment from which its meaning can be 
extracted [7].Lotman set up a communication model to do research into text semiotics and introduced the concept of semiosphere in the context of cultural semiotics. The basic insight behind Lotman's concept is that the minimum functional mechanism is not a single symbol, a single text, or a single semiotic system, but a complete semiotic space, whose internal organization is created and maintained by multiple semiotic processes, occurring at different levels of a multifaceted, multilevel communicative system [8].

\section{CONNOTATION, DENOTATION AND MYTH}

In semiotics, denotation and connotation are used to describe the relationship between the signifier and its signified, and the two types of signified are analyzed and distinguished: denotative signified and connotative signified. Both denotation and connotation are contained in meaning [9].

No symbol can be divorced from its denotational and connotational meanings, and since the speaker always uses symbols for a specific goal in a context, no symbol can be separated from the values of the speaker. Roland Barthes developed ansignifying model to deal with connotation and denotation[10]. He borrowed from Louis Hjelmslev the idea that signification is of different levels: the function of signification may be a single process, with denotation as the first step and connotation as the second [11]. The first level of significationis that of denotation: at this level, there is a symbol composed of the signifier and the signified. Connotation is the second level of signification that uses denotative symbols (signifier and signified) as its signifier and attaches to it an additional signified. In this framework, connotation is a symbol originated from a signifier of a denotative symbol (thus denotation results in a series of connotations). Barthes thinks that the levels of signification known as the denotation and connotation add up to generate ideology, which is characterized as the third level of signification, which may be the third step in world outlook where meta cognitive schema, such as freedom, sexuality, autonomy, etc. build a framework of reference, according to which these symbols maybe endowed with more abstract meanings, depending on the context [12], as in

\begin{tabular}{|c|c|c|c|}
\hline \multirow{3}{*}{ Language } & Signifier & Signified & \multirow[b]{2}{*}{ Signified } \\
\hline & Sign / & Signifier & \\
\hline & \multicolumn{3}{|c|}{ Sign } \\
\hline
\end{tabular}

Figure 1Connotation, Denotation and Myth

Myth is the symbol(sign) of greater cultural significance. In Barthes' view, myth serves the ideological function of naturalization [13]. Their function is to naturalize the culture, that is to say, to make the dominant cultural and historical values, attitudes and beliefs seem completely natural, thus objectively and truly reflecting "the way things are". Barthes described myth as a well-formed, complex system of communication that serves the ideological goals of the dominant class [6]. Myth is a particular way of signification in which the signifier is stripped of its history, the form is stripped of its substance, and then it is decorated with an artificial substance, but it appears completely natural. What a mythologist has to look at is not the mythological symbol, but the signifier, something that has been hollowed out. His role is to identify false symbols that masked their historical and social origins. Myth can be regarded as the extended metaphor. Like metaphors, myth helps us understand our experiences in a culture [14].

\section{SEMIOSPHERE}

Lotman's theory of cultural semiotics originates from a series of reflections on the general semiotic mechanism of culture by Lotman, and other figures of the Moscow-Tartu School in the 1970s. In Lotman's complex theoretical system of cultural semiotics, the concepts of second-order mode, cultural text, group memory, especially semiosphere, constitute the cornerstone of his theory, which deserves special attention.

The concept of semiosphere was first proposed by Yuri Lotman in the context of cultural semiotics. Semiosphere is the cultural semiotic continuum as understood by Lotman: the semiotic system is not single in meaning or clear in function, but contains multiple levels. As far as its isolated individual elements are concerned, it has no symbolic utility, and only by immersing itself in a specific semiotic continuum can it achieve its symbolic function. Here, the semiotic continuum is filled and constituted by a variety of forms and levels of semiotic patterns.

Semiosphere is a semiotic space with interdisciplinary attraction, necessary for the existence and operation of language and other semiotic systems, and the semiotic environment for the occurrence and generation of codes for communication. All semiotic systems are involved in a semiotic space and can only function through interaction with this space [15]. The basic idea behind this concept is that the smallest function mechanism is not a single symbol or single text or single semiotic system, but a complete semiotic space, whose internal organization is established and kept by multiple semiotic process, which happens in a multifaceted and multi-level communicative system of different levels. A symbol only makes sense in the context composed of other symbols. That is to say,semiosphere is a semiosis sphere and an experience. In itself, this is a prerequisite for interpreting any single act of communication as one[16]. 
Semiosphere is inclined to replace the dualistic categories left over from structuralism and supply a potential basis for local investigations carried out by cultural research. It attaches importance to the transformation of boundary and hierarchy, displacement between the center and the periphery, mediationand translation, isomorphic relationship between events on micro and macro levels, and unity by diversity. The semiospherepreexists and constantly interacts with language, which interprets why the code is constantly updated. The "foreign", "asymmetric" and "peripheral" texts constantly reconstruct the whole culture into the "central" culture [15].

Lotman alluded those semiospheres as controlling the operation of languages in the range of cultures. John Hartley explained that there are multiple levels at which a semiosphere can be identified----at the level of a single ethnic or linguistic culture, for example, or of greater unity such as "the East" until "species"; we can similarly describe the semiosphere at a particular time in history[17]. This concept of a semiosphere provides a more unified and dynamic view of semiosis than the research into a particular medium as if each existed in a vacuum.

\section{CONCLUSION}

This study expatiates on some key concepts in cultural semiotics, analyzes the characteristics and functions of cultural semiotics, and indicates the importance of semiotic analysis. It elaborates Roland Barthes' theoretical framework of the three levels based on social or cultural phenomena, which finds out the upper isomorphism system of the myths in the culture, so as to analyze the systematic and structural features of culture with cultural codes. Lotman'sSemiosphere is a concept of cultural space, in which symbols form texts, texts form cultures, and cultures form semiospheres. Semiosphere is the culture of all cultures. Lotman's original thoughts on the semiosphere theory are of great significance for us to renew and deepen our understanding of cultural space and to recognize human culture in essence.

In a nutshell, cultural semiotics is important because it teaches us that our work has no meaning outside the complex set of factors of culture. These factors are not static, but rather constantly changing because we are changing and creating them. The more we understand and recognize these factors, the more control we will have over the success of the products we create.

\section{ACKNOWLEDGMENTS}

I would like to thank Professor HuShu Zhong, who was kind and gracious, and I often feel that he was strict with me in the process of communicating with him. Starting from the selection of the topic for this paper, he constantly gave me inspiration and direction in choosing the topic and various methods on how to determine the content of my research. Throughout the process of writing and revising, he worked tirelessly to review and helped me clarify my ideas so that this paper could be successfully completed.

\section{REFERENCES}

[1] Johansen, Jørgen Dines, and Svend Erik Larsen. Signs in Use. New York: Routledge, 2002.

[2] Danesi, Marcel. Messages and Meanings: An Introduction to Semiotics. Toronto: Canadian Scholars' Press, 1994

[3] Scott, Linda M. "Images in Advertising: The Need for a Theory of Visual Rhetoric." Journal of Consumer Research21(1994): 252-73.

[4] Eco, Umberto. "Looking for a Logic of Culture." Times Literary Supplement 5 and 12 Oct. 1973: 1150 .

[5] Tylor, E B. Primitive Culture. London: John Murray, 1871.

[6] Maasik, Sonia, and Jack Solomon. Signs of Life in the U.S.A. Boston: Bedford/St, 2000.

[7] Schonle, Andreas, ed. Lotmanand Cultural Studies: Encounter and Extensions. Wisconsi: University of Wisconsin Press, 2006.

[8] Lotman, Yuri M. “On semiosphere.” Sign System Studies 17 (1984): 6-23.

[9] Chandler, Daniel. Semiotics for Beginners. URL http: //www. aber. ac. uk/ media / Documents /S4B /Retrieved 2020-02-06.

[10] Barthes, Roland.Mythologies, Trans. Annette Lavers. 1972. New York: Hill and Wang, 1957.

[11] Hjelmslev, Louis. Prolegomena to a Theory of Language. 1943. Whitfield. Madison: University of Wisconsin Press, 1961.

[12] O'Sullivan, Tim, et al. Key Concepts in Communication and Cultural Studies. London: Routledge, 1994

[13] Barthes, Roland. "The Rhetoric of the Image" in Image, Music, Text. Trans. Stephen Heath. Hill and Wang, 1977.

[14] Lakoff, George, and Mark Johnson. Metaphors We Live By. Chicago: University of Chicago Press, 1980.

[15] Lotman, Yuri M.Universe of the Mind: A Semiotic Theory of Culture. Trans. Ann Shukman. London: I. B. Tauris \& Co. Ltd Publishers, 1990. 
[16] Brown, Keith. Encyclopedia of Language \& Linguistics, $2^{\text {nd }}$ ed. 14 vols. Oxford: Elsevier Ltd., 2006.

[17] Hartley, John. Popular Reality: Journalism, Modernity, Popular Culture. London: Arnold, 1996. 